
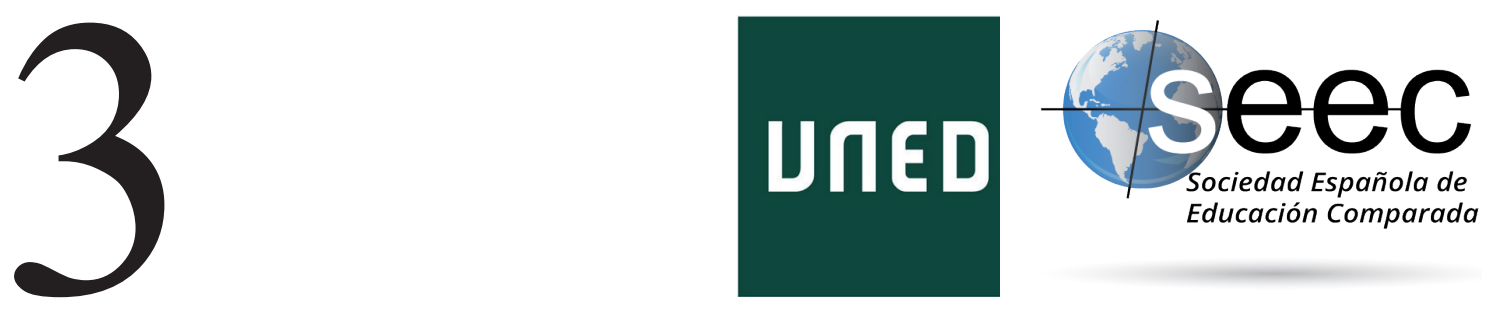

\title{
Influencia supranacional de la UNESCO en la educación superior Latinoamericana en el nuevo Milenio
}

Supranational influence of UNESCO in Latin American higher education

\section{Ricardo Gaete Quezada*}

DOI: 10.5944/reec.37.2021.27884

Recibido: 11 de julio de 2020 Aceptado: 5 de agosto de 2020

\footnotetext{
*Ricardo Gaete Quezada: Académico del Departamento de Ciencias Sociales, Facultad de Ciencias Sociales, Artes y Humanidades, de la Universidad de Antofagasta - Chile desde 1998. Investigador en las temáticas de responsabilidad social y enfoque de género en la educación superior. Datos de contacto: e-mail: ricardo. gaete@uantof.cl
} 


\title{
Resumen
}

La educación superior latinoamericana en las últimas décadas ha experimentado las principales tendencias mundiales: masificación del acceso de los estudiantes, insuficiente financiamiento estatal, aumento de instituciones privadas en el sistema educativo terciario, consideración como un bien público garantizado por el Estado, aumentando la relevancia de la misión universitaria en la solución de las necesidades globales. Mediante el método comparativo desarrollado a través de un análisis documental para el período 1998 al 2018, se analiza la influencia en Latinoamérica de la Política Supranacional de la UNESCO de responsabilidad social de las instituciones de educación superior. Los resultados, evidencian dicha influencia en la Región, a través de las Declaraciones de las Conferencias Mundiales de Educación Superior de la UNESCO, materializada en las acciones desarrolladas por el Instituto Internacional para la Educación Superior en América Latina y el Caribe (IESALC), tales como la realización de las Conferencias Regionales de Educación Superior o la creación del Observatorio Regional de Responsabilidad Social para América Latina y el Caribe (ORSALC). Dicha influencia supranacional ha generado un debate académico respecto del concepto de responsabilidad social universitaria, instaurado en la Región desde inicios del nuevo Milenio, relacionado con la gestión de los impactos del quehacer universitario en sus partes interesadas, evolucionando hacia el reconocimiento de la educación superior como un bien público y un derecho humano como expresión de una responsabilidad social territorial, para contribuir efectivamente al logro de los Objetivos de Desarrollo Sostenible 2030. Se concluye que la Política Supranacional analizada, debe consolidar su influencia en Latinoamérica a largo plazo, implementando acciones estratégicas clave, como el fortalecimiento del Espacio Latinoamericano de Educación Superior o la investigación sobre las aportaciones que las universidades latinoamericanas deben efectuar para garantizar efectivamente a la educación superior como un bien común en la Región.

Palabras clave: Educación Superior; Política Educativa Supranacional; responsabilidad social; UNESCO.

\begin{abstract}
Latin American higher education in recent decades has experienced the main world trends: massification of student access, insufficient state funding, increase of private institutions in the tertiary education system, as well as a regional debate on its consideration as a good public guaranteed by the State, increasing the relevance of the university mission in solving global needs. Through the comparative method developed through a documentary analysis for the period 1998 to 2018, the influence in Latin America of the Supranational Policy on social responsibility of UNESCO higher education institutions is analyzed. The results show this influence in the Region, through the Declarations of the UNESCO World Conferences on Higher Education, materialized in the actions developed by the International Institute for Higher Education in Latin America and the Caribbean (IESALC), such as the holding of the Regional Conferences on Higher Education or the creation of the Regional Observatory of Social Responsibility for Latin America and the Caribbean (ORSALC). In addition, there is an academic debate between the concept of university social responsibility, established in the Region since the beginning of the new Millennium, related to managing the impacts of university work on its stakeholders, evolving towards the recognition of higher education as a good public and a human right as an expression of a territorial social responsibility, effectively contributing to the achievement of the 2030 Sustainable Development Goals. It is concluded that the analyzed Supranational Policy must consolidate its influence in the Region in the long term, by implementing some actions key strategies, such as strengthening the Latin American Higher Education Area or research on the contributions that Latin American universities must make to effectively guarantee higher education as a common good in the Region.
\end{abstract}

Keywords: Higher Education; digital capitalism; metrics; academics; Academia.edu; ResearchGate. 


\section{Introducción}

La Supranacionalidad es un concepto utilizado originalmente en el Derecho Constitucional e Internacional o en Ciencias Políticas. Se refiere a los procesos de globalización e integración política, social, económica y cultural, desarrollados a nivel mundial, por ejemplo la Unión Europea (Biacchi, Carta y Buttendorff, 2018; Carrasco, 2017; D’Ascanio, 2017; Matarranz y Valle, 2018; Mendivil, 2010; Pereira, 2012; Ramos, 2011; Torres, 2012).

Como plantean Matarranz y Valle (2018), los organismos supranacionales surgen desde finales de la Segunda Guerra Mundial, para asegurar la paz, el diálogo y solidaridad de la humanidad. También, señalan que la primera vez que se utiliza el término supranacionalidad, fue en el Tratado Internacional que crea la Comunidad Europea del Carbón y el Acero (CECA) el año 1951, otorgando poder de decisión y soberanía a dicho organismo supranacional, mayor que el ostentado individualmente por cualquiera de sus Estados miembros (Carrasco, 2017; Ramos, 2011; Valle y Manso, 2013).

Según Mendivil (2010), el Estado Supranacional es resultado de la «atribución-cesión de competencias» de soberanía nacional, transfiriendo poder de decisión hacia el nuevo ordenamiento normativo de carácter supranacional, basado en tres grandes características: reconocimiento de intereses y valores comunes del proyecto integracionista; respeto de las decisiones y normas supranacionales y existencia de autonomía relativa del poder cedido al ente supranacional.

Además, Ramos (2011) afirma que para que la supranacionalidad sea materializada es necesario crear un órgano comunitario, depositario de las competencias para tomar decisiones de aplicación inmediata, en un ejercicio de sesión de soberanía que según Biacchi et al. (2018) debe privilegiar permanentemente la protección de los derechos humanos y la democracia de los países que integran el bloque supranacional.

Asimismo, Pereira (2012) afirma que la supranacionalidad incorpora indisolublemente tres grandes elementos: soberanía, nacionalidad y territorialidad. Además, el mismo autor afirma que las instituciones supranacionales trascienden las estructuras e intereses nacionales de los estados-miembros, conformándose una realidad político-cultural que establece una identidad heterogénea, diversa y multicultural, cuyo propósito fundamental es garantizar los derechos relativos a la dignidad humana.

En síntesis, como señalan Biacchi et al. (2018), para que las políticas supranacionales puedan ser implementadas efectivamente «...se hace necesario el constante diálogo entre el ordenamiento jurídico supranacional y los ordenamientos jurídicos de los Estados miembros del bloque que, por su vez, deberán aceptar -en sus ordenamientos jurídicosla adopción de tales políticas y legislación» (p.103).

Así, el artículo intenta responder a la siguiente interrogante: ¿Cómo la influencia supranacional de la UNESCO ha contribuido a la configuración de la política de educación superior socialmente responsable en Latinoamérica? El objetivo del trabajo es analizar la influencia supranacional de la UNESCO en Latinoamérica en la configuración de la política de educación superior socialmente responsable en el nuevo milenio, mediante un análisis documental de tipo cualitativo de las declaraciones y publicaciones de dicho organismo supranacional, así como de las leyes de educación superior de países latinoamericanos.

En la primera parte del trabajo, se exponen los aspectos más relevantes del marco teórico explicativo del estudio: política educativa supranacional (PES) y responsabilidad social de la educación superior (RSES). Luego, se describen los materiales y métodos para 
realizar la investigación, así como los países latinoamericanos incluidos en la muestra. Finalmente, se presentan los resultados y discusión relacionados con la implementación de la PES sobre RSES de la UNESCO.

\subsection{La supranacionalidad como política educativa}

La supranacionalidad es descrita por Valle (2012) en el ámbito de la educación, expresada como PES, es decir: «...cualquier acción en materia educativa, o de enseñanza o formación, que se ponga en marcha desde estos organismos [supranacionales], o bien cualquier propuesta que surja desde ellos como recomendación de carácter global» (p.117). Según el mismo autor, la PES se relaciona con tres conceptos: 1) política educativa (realidad política educativa nacional), 2) educación comparada (estudio de diferentes sistemas educativos nacionales), y 3) educación internacional (armonización de estructuras y currículos educativos a nivel global).

La Figura 1, resume los principales elementos de la PES concebida como un campo de investigación, que analiza su impacto y reducción de la centralidad de los Estados nacionales en el diseño e implementación de sus propias políticas educativas (Carrasco, 2017; Valle, 2012; Represas, 2015a).

Contexto de la PES

- Descripción e identificación histórico-descriptiva de acciones, programas y planes concretos en el ámbito educativo y formativo, impulsados por los organismos internacionales.

Análisis comparado

- Comparacion de las PEs desarrolladas por diferentes organismos internacionales a nivel mundial.

Replicabilidad

- Análisis de la implementación de las PES de los organismos internacionales, convertidas en corrientes educativas globales.

Impacto

- Efectos y consecuencias de PES implementadas por organismos internacionales, en los sistemas educativos nacionales específicos como casos individuales.

Parámetros interpretativos

- Actores (Instituciones, Lobbys, Estados miembros)

- Dinámicas del Diseño de las políticas (seguimiento normativo y documental de los acuerdos y marcos relacionados con la política)

- Dinámicas de ejecución de las políticas (formas de implementar una acción política por cada organismo supranacional)

- Las Ideologías (existencia de múltiples ideologías de los actores que están interesados en las acciones políticas ejecutadas por el ente supranacional)

- Los valores (hechos y fenómenos culturales de cada país y actores que inciden en las confrontaciones y consensos asociados con las acciones políticas implementadas)

- Los sistemas educativos (implica el análisis de fenómenos y factores tales como: fines de la educación, estructura, currículo, formación docente, dirección escolar, financiación, etc.)

- El contexto (condiciones temporales e históricas nacionales e internacionales, existentes al momento de diseñar y ejecutar las PES)

Figura 1. Elementos de la PES como campo de estudio. Elaboración propia, basado en Valle (2012) y Represas (2015a). 
Además, Matarranz y Valle (2018) afirman que el concepto de PES implica: «... estudiar los fenómenos educativos a nivel internacional, superando así las barreras nacionales, y tratando de detectar cuál es el impacto que tienen en los sistemas educativos nacionales las políticas educativas que emanan de los organismos internacionales y supranacionales» (pp.100-101). Los mismos autores, señalan que la PES es un ámbito de estudio emergente, considerando como sus principales ámbitos: análisis de las políticas educativas de organismos supranacionales; perspectiva comparada de las mismas y estudio de su impacto en los sistemas educativos nacionales.

Así, existen diferentes organismos supranacionales que han desarrollado PES en las últimas décadas a nivel mundial, entre los que destacan: Organización para la Cooperación y el Desarrollo Económico (OCDE), Banco Mundial, Organización de Estados Iberoamericanos para la Educación, la Ciencia y la Cultura (OEI), Organización de las Naciones Unidas para la Educación, la Ciencia y la Cultura (UNESCO), Fondo de las Naciones Unidas para la Infancia (UNICEF), Unión Europea, entre otros (Carrasco, 2017; Dávila, Naya y Altuna, 2015; Represas, 2015a y 2015b; Valle 2012).

Según Fernández y Coppola (2013), actualmente son ejemplos de PES, la aplicación de pruebas internacionales de rendimiento escolar como TIMSS o PISA, así como la existencia de Agencias internacionales de acreditación como la International Network for Quality Assurance Agencies in Higher Education (INQAAHE). También, Valle y Manso (2013) destacan la PES sobre formación por competencias desarrollada por la Unión Europea (Matarraz, Valle y Manso, 2020).

Además, la supranacionalidad es un aspecto distintivo del denominado «Espacio Europeo de Educación Superior» (EEES), instancia supranacional mediante la cual se implementan el Proceso de Bolonia (1999) o la Estrategia de Lisboa (2000) en Europa (Carrasco, 2017; Colomo y Esteban, 2020; Matarranz, Valle y Manso, 2020; Valle, 2012), para configurar una universidad europea al servicio de la sociedad del conocimiento en Europa (D’Ascanio, 2017).

En América Latina, Fernández y Coppola (2013) identifican diferentes desafíos para constituir un «Espacio Latinoamericano de Educación Superior», similar al desarrollado en Europa, en proyectos regionales como el Mercado Común del Sur (MERCOSUR) o Unión de Naciones Suramericanas (UNASUR): 1) heterogeneidad de los modelos institucionales de universidad; 2) organización de los estudios de pre y postgrado; y 3) diferentes sistemas de educación a distancia, de aseguramiento de la calidad, etc.

\subsection{UNESCO y la Responsabilidad Social de la Educación Superior}

La RSES es promovida a nivel mundial por la UNESCO mediante las Conferencias Mundiales de Educación Superior (CMES) de los años 1998 y 2009 respectivamente, ofreciendo una serie de lineamientos que han orientado el desarrollo conceptual y metodológico de dicho campo de estudio (Gaete, 2016; Grimaldo, 2017; Larrán y Andrades, 2017; Licandro y Yepes, 2018; Martí-Noguera, Martí-Vilar, Vargas Villamizar y MoncayoQuevedo, 2014; Navarro, Rubio, Lavado, Minnicelli y Acuña, 2017; Urdaneta, Cova, Chirinos y González, 2016).

Por otra parte, la RSES o Responsabilidad Social Universitaria (RSU) es un campo científico joven, que adquiere relevancia global a partir de los lineamientos y propuestas que desde finales de la década de los noventa del siglo XX, elaboran diferentes organismos supranacionales como el Banco Interamericano de Desarrollo (BID) (Gaete y Álvarez, 2019; Duque y Cervantes-Cervantes, 2020; Ruiz-Corbella y Bautista-Cerro, 2016). 
Según el estudio bibliométrico de la producción científica sobre la RSU desarrollado por Duque y Cervantes-Cervantes (2020), en el período 2000-2020 fueron publicados 200 artículos en las bases de datos Web of Science (WOS) y SCOPUS. Dicho estudio establece una tendencia lineal creciente los últimos cinco años, siendo España el país que concentra la mayor producción científica sobre la RSU, mientras que los países latinoamericanos acumula el 80 \% del total. Además, identifican a François Vallaeys como el autor más citado e influyente en este campo de estudio, situando a la CMES del año 2009, como un documento clásico para el estudio de la RSU.

Otros estudios bibliométricos previos sobre la RSU, como el desarrollado por Larrán y Andrades (2017), analiza la productividad científica en 15 revistas especializadas en educación superior (ES), durante el período 2000-2015. Según estos autores, se produce un proceso de cambio en la respuesta universitaria frente a las demandas de la sociedad, avaladas por iniciativas institucionales tales como la Declaración de la CMES de 1998 de la UNESCO o el Plan Bolonia de la Unión Europea.

Previamente, Piacenza y Silva (2013) desarrollaron el primer estudio bibliométrico sobre la RSU en el ámbito latinoamericano, para el período comprendido entre los años 2002 al 2012, identificando un total de 94 documentos relacionados con dicha temática, siendo el año 2010 el que registra la mayor cantidad de artículos publicados donde Venezuela, Colombia y México acumulaban la mayor productividad, considerando el país de las revistas en donde se publicaron los trabajos.

Los estudios bibliométricos reseñados anteriormente sobre la literatura relativa a la RSES, confirman su creciente relevancia a nivel latinoamericano en las últimas dos décadas, como el contexto en el cual se analiza en el presente trabajo a la PES de la UNESCO relacionada con dicha temática.

\section{Materiales y Métodos}

El trabajo considera la propuesta metodológica sobre la investigación de las PES elaborada por Valle (2012), descrita anteriormente en la Figura 1. Así, se desarrolla un análisis documental de tipo cualitativo, que incluye entre otras fuentes de información: Declaraciones CMES de la UNESCO, Informes de las Conferencias Regionales de Educación Superior (CRES) de la UNESCO, y la literatura científica relacionada con la RSES o la RSU. Para obtener la documentación antes señalada, se utiliza la base de datos UNESDOC administrada por la UNESCO (Represas, 2015a).

También, se analizan las Leyes de ES de los países latinoamericanos expuestas en la Figura 2, para identificar el impacto de la PES sobre RSES de la UNESCO en los sistemas de ES de la Región, materializado en cambios legales que reflejen dicha influencia supranacional, incorporando la RSES como aspecto legal del funcionamiento de las Instituciones de Educación Superior (IES) latinoamericanas. 


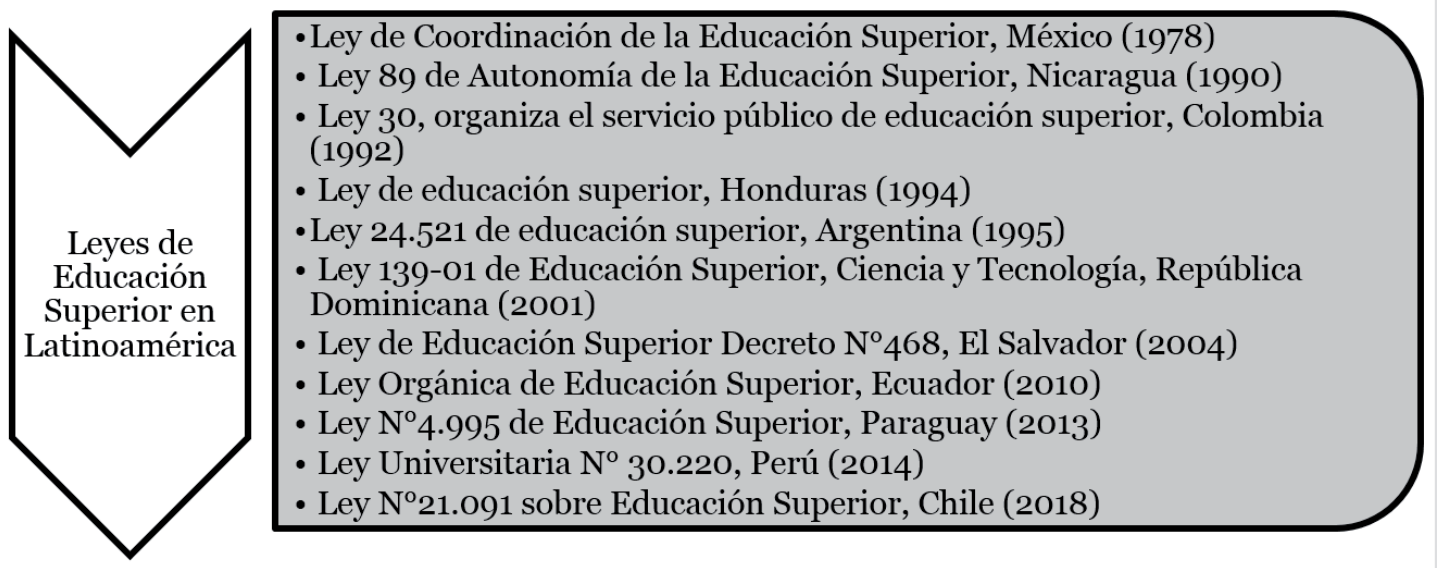

Figura 2. Leyes de ES de países Latinoamericanos. Elaboración propia.

Así, se incluyen únicamente las Leyes de ES como expresión de lo que Villanueva (2010) denomina «desregular a través de regulaciones», es decir: «...se intentaba sentar las bases de nuevos ordenamientos normativos que permitieran en algún sentido dar inicio a un nuevo período para las universidades latinoamericanas» (p.89), razón por lo que cual no se analizan otras fuentes legales tales como leyes generales de educación, Constitución Política u otras que regulen aspectos del funcionamiento de las IES de manera más general.

El procedimiento de análisis de cada una de las Leyes de ES, considera la identificación de los aspectos planteados en la Figura 4 del trabajo, en cada uno los artículos que integran los cuerpos legales incluidos en la Figura 2, elaborando fichas de análisis por cada ley en el software MS EXCEL.

Además, el análisis de los resultados de la revisión documental será expuesto en cuatro sub-apartados, según lo indicado previamente en la Figura 1, es decir: 1) Contexto de la PES sobre RSES de la UNESCO; 2) Análisis comparado de las PES sobre RSES de otros organismos supranacionales; 3) Replicabilidad de la PES sobre RSES de la UNESCO en Latinoamérica; y 4) Impacto de la PES sobre RSES de la UNESCO en los sistemas de ES latinoamericanos. Igualmente, se analizan de manera transversal los siete parámetros interpretativos en los cuatro sub-apartados de la PES: Actores, Dinámicas de diseño y ejecución de las políticas, ideologías, valores, sistemas educativos y contexto.

\section{Resultados}

\subsection{Contexto de la PES sobre RSES de la UNESCO}

Como señala Represas (2015a), la UNESCO posee una estructura organizacional integrada por extensas redes institucionales, creadas para la promoción de la Educación a nivel mundial. En la Figura 3, se identifican los órganos rectores de la UNESCO, para el cumplimiento de su misión institucional de asegurar el acceso igualitario a la educación para todos y todas, considerando valores tales como: libertad, igualdad, respeto y comprensión mutua. 


\section{CONFERENCIA GENERAL}

(Constituida por representates de los estados miembros, orienta los programas sometidos al ConsejoEjecutivo, revisa los informes nacionales)

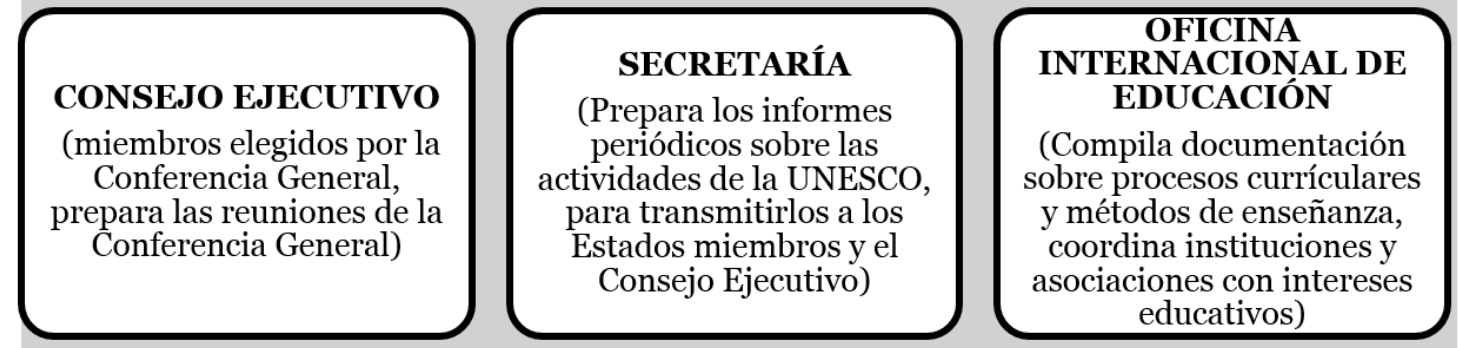

Figura 3. Principales órganos rectores de la UNESCO. Elaboración propia, basado en Represas (2015a).

Según Represas (2015a), uno de los instrumentos normativos que le permiten a la UNESCO alcanzar acuerdos transversales son las:

«Declaraciones», entendidas como «...otra manera de establecer normas que no están sujetas a ratificación [...] enumeran los principios universales que la comunidad de Estados tiene la intención de reconocer la mayor autoridad y dar el más amplio apoyo» (p.107). La misma autora, señala que tanto convenios, recomendaciones como declaraciones cuentan mayormente con fuerza moral, más que normativa (López, 2012; MartíNoguera et al., 2014).

La primera CMES del año 1998, se desarrolló en un contexto educativo marcado por la influencia del Banco Mundial, entidad que desarrollaba una PES orientada hacia la privatización de la ES a nivel global (Tünnermann, 2010). Así, Zamudio y Figueroa (2020) afirman que en virtud de lo planteado en esta Conferencia, las IES deben ampliar su misión hacia dos temas adicionales: desarrollo sostenible y mejoramiento de la sociedad (Larrán y Andrades, 2017).

Además, Diago (2013) señala que la ES mundial evidenciaba un fuerte crecimiento en la cantidad de estudiantes matriculados, contrastada con la necesidad de asegurar mayores fuentes de financiamiento, igualdad en el acceso y calidad de formación, razón por la cual, la CMES de 1998 fijó los principios que orientarían a la ES mundial en el siglo XXI.

Según Tünnermann (2010), en la CMES participaron 4.00o representantes de diferentes regiones del mundo, para analizar diversas temáticas relevantes para las IES, tales como: pertinencia, calidad, gestión, financiamiento e internacionalización de la ES, desarrollo humano sostenible, formación docente y la RSES, entre otras. Así, una de las claves del éxito de la CMES del 1998, fue la realización de una serie de Conferencias Regionales previas (Diago, 2013), que nutrieron de los insumos necesarios para desarrollar las diferentes mesas redondas y demás actividades programadas para la CMES.

Según López (2012), la segunda CMES del año 2009 desarrollada en París, registró 1.200 participantes aproximadamente, pertenecientes a 150 estados miembros de la UNESCO, incluyendo representantes de organismos internacionales, de ONGs, la sociedad civil y el sector privado. Sin embargo, Tünnermann (2010) describe que el contexto global en el cual se desarrolla la CMES del 2009, estuvo marcado por la crisis económica del año 2008 a nivel mundial, lo que orientó el debate hacia el rol que la ES debía asumir para enfrentar las amenazas de una recesión mundial y sus efectos en el funcionamiento de las IES. 
Además, López (2012) señala que la CMES del 2009 se contextualiza en un escenario de sostenida masificación de la ES en la última década, complementado por las crecientes dificultades estatales para financiar dicha expansión de la matrícula, el aumento de la participación de universidades privadas en ES y por ende, una mayor mercantilización, así como la creciente relevancia de los procesos de acreditación de la calidad, como nuevas dinámicas de la ES y la investigación a nivel mundial en dicho período, transformándose en los temas centrales de la discusión de la CMES ese año.

Como Tünnermann (2010, p.44) señalan, la CMES del año 2009 se centró en tres grandes temáticas: 1) Rol de la Educación Superior respecto de los grandes desafíos mundiales; 2) la RSES y el compromiso de la sociedad con las IES; y 3) promoción de la excelencia de la ES en África y la creación de un espacio africano de ES e investigación.

También, se destaca la publicación del Informe «La Educación Superior en tiempos de cambio. Nuevas dinámicas para la responsabilidad social», editado por la Global University Network for Innovation (GUNI), como una actividad preparatoria de la CMES del 2009 para describir los cambios en los sistemas de ES a nivel mundial, destacando entre otros: incremento de la demanda, reducción del papel del Estado y aparición del mercado, diversificación de proveedores privados, internacionalización y educación transfronteriza, acreditación de la calidad y rankings.

Así, como se observa en la Figura 4, la UNESCO a través de las Declaraciones de ambas CMES, estableció los principales lineamientos que han configurado el concepto de RSES en las últimas dos décadas (Duque y Cervantes-Cervantes, 2019; Gaete, 2014 y 2016; Gómez, Alvarado y Pujols, 2018; Grimaldo, 2017; Licandro y Yepes, 2018; Martí-Noguera y Martí-Vilar, 2013; Martí-Noguera, Martí-Vilar, Vargas Villamizar y Moncayo-Quevedo, 2014; Martí-Noguera y Martí-Vilar, 2013; Martí-Noguera, Calderón y Fernández-Godenzi, 2018; Navarro, Rubio, Lavado, Minnicelli y Acuña, 2017; Salazar, 2016; Soto, 2018; Urdaneta, Cova, Chirinos y González, 2016; Valarezo y Túñez, 2014). 


\section{Declaración Conferencia Mundial de Educación Superior, 1998}

-Art. 9, letra b: Las instituciones de educación superior deben formar a los estudiantes para que se conviertan en ciudadanos bien informados y profundamente motivados, provistos de un sentido crítico y capaces de analiar los problemas de la sociedad, buscar soluciones para los que se planteen a la sociedad, aplicar éstas y asumir responsabilidad sociales.

-Art. 13, letra c: El objetivo último de la gestión debería ser el cumplimiento óptimo de la misión institucional asegurando una enseñanza, formación e investigación de gran calidad, y prestando servicios a la comunidad. Este objetivo requiere una dirección que combine la visión social, incluida la comprensión de los problemas mundiales, con competencias de gestión eficaces. La función de dirección en la enseñanza superior constituye, por tanto, una responsabilidad social de primer orden y puede reforzarse de manera significativa a través del diálogo con todos los que participan en ella, y en particular con los profesores y los estudiantes. Teniendo presente la necesidad de mantener dentro de límites razonables las dimensiones de los órganos rectores de los establecimientos de enseñanza superior, habría que prever la participación de los académicos en dichos órganos, en el marco institucional vigente.

\section{Declaración Conferencia Mundial de Educación Superior, 2009}

- La responsabilidad social de la educación superior:

- 1) La educación superior, en tanto que bien público, es responsabilidad de todas las partes interesadas, en particular de los gobiernos.

- 2) Ante la complejidad de los desafíos mundiales, presentes y futuros, la educación superior tiene la responsabilidad social de hacer avanzar nuestra comprensión de problemas polifacéticos con dimensiones sociales, económicas, científicas y culturales, así como nuestra capacidad de hacerles frente. La educación superior debería asumir el liderazgo social en materia de creación de conocimientos de alcance mundial para abordar retos mundiales, entre los que figuran la seguridad alimentaria, el cambio climático, la gestión del agua, el diálogo intercultural, las energías renovables y la salud pública.

-3) Los centros de educación superior, en el desempeño de sus funciones primordiales (investigación, enseñanza y servicio a la comunidad) en un contexto de autonomía institucional y libertad académica, deberían centrarse aún más en los aspectos interdisciplinarios y promover el pensamiento crítico y la ciudadanía activa, contribuyendo así al desarrollo sostenible, la paz y el bienestar, así como a hacer realidad los derechos humanos, entre ellos la igualdad entre los sexos.

-4) La educación superior debe no sólo proporcionar competencias sólidas para el mundo de hoy y de mañana, sino contribuir además a la formación de ciudadanos dotados de principios éticos, comprometidos con la construcción de la paz, la defensa de los derechos humanos y valores de la democracia.

-5) Existe la necesidad de lograr más información, apertura y transparencia en lo tocante a las diversas misiones y actuaciones de cada establecimiento de enseñanza.

-6) La autonomía es un requisito indispensable para que los establecimientos de enseñanza los puedan cumplir con su cometido gracias a la calidad, la pertinencia, la eficacia, la transparencia y la responsabilidad social.

Figura 4. RSES en las CMES, UNESCO 1998 y 2009. Elaboración Propia.

Así, la Figura 4 evidencia la importante ampliación y explicitación que se produce en el discurso de la UNESCO sobre la RSES, identificando con mayor claridad la manera de entender e implementar dicho concepto en el funcionamiento de las IES.

Según Tünnermann (2010), el reconocimiento explícito de la UNESCO del concepto de RSES fue uno de los puntos más importantes de la Declaración de la CMES del año 2009. Precisamente, las IES tienen la responsabilidad social de generar conocimiento para comprender las dimensiones sociales, económicas, científicas y culturales de los desafíos globales, en problemáticas tales como: seguridad alimentaria, cambio climático, manejo del agua, diálogo intercultural, generación de energías renovables y salud pública.

Sin embargo, la evolución del concepto de RSES emanado desde la CMES de la UNESCO del 2009, no ha estado exento de críticas y cuestionamientos, relacionados con las diferentes ideologías neoliberales que están relacionadas con la aplicación de dicho enfoque al ámbito universitario (Larrán y Andrades, 2017; Martí-Noguera, Calderón y Fernández-Godenzi, 2018; Martí-Noguera y Gaete-Quezada, 2019; Vallaeys, 2018). 
Según Calderón, Pedro y Vargas (2011), la Declaración de la CMES del año 1998 asignaba un rol más preponderante al Estado respecto de la ES como derecho humano, mientras que la Declaración de la CMES de 2009 evidencia una perspectiva más neoliberal asignada a la ES a nivel mundial, entendida como un bien económico que se ha privatizado (Beltrán-Llevador, Íñigo-Bajo y Mata-Segreda, 2014; Gaete, 2016; Martí-Noguera, Calderón y Fernández-Godenzi, 2018).

También, es importante rescatar la reflexión sobre los discursos de ES desarrollada por Martí-Noguera et al. (2014), relativa a los aportes de la UNESCO mediante las Declaraciones de las CMES del 1998 y el 2009, señalando que este tipo de discursos:

«Emanados de instituciones internacionales variopintas compuestas por representantes de diferentes países, sectores y gremios- no emiten políticas sino directrices que inciden en la creación de políticas, siendo un elemento común en el discurso actual la promoción del concepto de competencia que [...] pone al servicio del mercado laboral un constructo psicológico con una finalidad fundamentada en un modelo económico» (p.37).

Así, la mercantilización de la ES y el origen empresarial del modelo de responsabilidad social, ha estado presente desde el inicio de su aplicación al ámbito de la ES mundial, generando un importante debate académico respecto de la conveniencia de su implementación, especialmente cuando se pretende aplicar dicho concepto a las IES de carácter estatal (Calderón et al., 2011; De la Cruz y Sasia, 2008; Gaete, 2020; Tünnermann, 2010; Vallaeys, 2018).

\subsection{Análisis comparado de las PES sobre RSES}

Según Represas (2015b), el análisis de la PES debe incluir las acciones desarrolladas por diferentes organismos supranacionales en el ámbito educativo (Ruiz-Corbella y Bautista-Cerro, 2016), tales como la OCDE, Unión Europea o la UNESCO, que en las últimas décadas han implementado diversas políticas para orientar el funcionamiento de las IES a nivel global.

En el caso de la Unión Europea, la PES desde inicios del nuevo Milenio identifica a la ES como pilar fundamental para alcanzar una economía más competitiva basado en el conocimiento, complementado con los propósitos originales de fomentar la paz y el progreso a nivel mundial, que motivaron la creación de dicho ente supranacional. Así, la ES y la formación profesional adquieren una importancia fundamental, a partir del modelo basado en las competencias laborales (Colomo y Esteban, 2020; Represas, 2015b; Matarraz, Valle y Manso, 2020; Valle y Manso, 2013).

En lo relativo a la RSES en Europa, la Universidad Politécnica de Bucarest lideró el proyecto denominado «EU-USR» entre los años 2012-2014 (Ruiz-Corbella y BautistaCerro, 2016), financiado por la Comisión Europea para desarrollar un marco de referencia común de RSU para las universidades europeas, basado en cuatro pilares fundamentales, identificados en la Figura 5. 


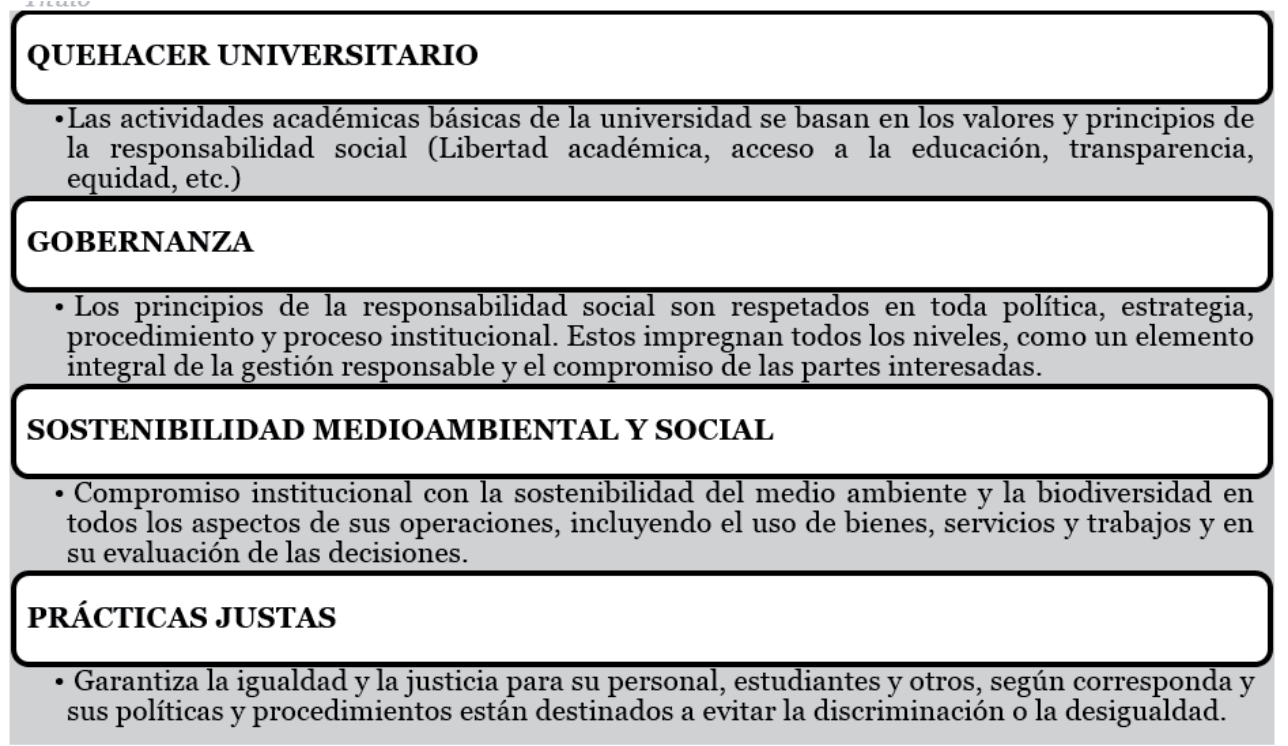

Figura 5. Estándares Marco de Referencia común de la RSU en la Unión Europea. Elaboración propia, basado en Dima (2015).

Además, el proyecto EU-USR define a la RSU como «...las responsabilidades que tienen las universidades sobre las repercusiones que puedan tener sus decisiones y actividades sobre la sociedad y el medio ambiente mediante el uso de estrategias transparentes y éticas» (Dima, 2015, p.4). Asimismo, Larrán y Andrades (2017) señalan que el Proceso de Bolonia de la Unión Europa incluye acciones para el fomento de los valores cívicos y sociales, en los planes de estudio de las universidades europeas, lo que establece un pilar importante para el fortalecimiento de la RSES en la formación de profesionales universitarios socialmente responsables a nivel europeo.

También, es posible destacar el caso español relacionado con la implementación de la Estrategia Universidad 2015, donde la responsabilidad social es identificada como un aspecto relevante para la identidad y el aseguramiento de la calidad de las universidades españolas, como expresión de su tercera misión (Gaete, 2014; González, Fontaneda, Camino y Revilla, 2015; Ruiz-Corbella y Bautista-Cerro, 2016; Vallaeys, 2014). En los últimos años, existen diversas investigaciones sobre la RSU de las IES españolas, describiendo los avances en la aplicación de dicho modelo al ámbito universitario español (Gómez et al., 2018; González et al., 2015; Martínez-Usarralde, Lloret-Catalá y Mas-Gil, 2017; Ruiz-Corbella y Bautista-Cerro, 2016; Vázquez, Aza y Lanero, 2014).

En lo relativo a la OCDE, la PES incluye la estandarización de la información sobre los procesos educativos a nivel mundial, mediante diferentes instrumentos de evaluación tales como el Programa PISA (Programme for International Student Assessement), o la Prueba TALIS (Teaching and Learning International Survey), para orientar los esfuerzos en la configuración del modelo de formación por competencias laborales, como eje del modelo educativo a nivel mundial (Fernández-Díaz, Rodríguez-Mantilla y MartínezZarzuelo, 2016; Ministerio de Educación y Formación Profesional, 2019; OCDE, 2018; Represas, 2015b).

Según Represas (2015b), el paradigma educativo promovido por la OCDE, se relaciona con el aprendizaje permanente para tener empleo a lo largo de la vida, intentando vincular más estrechamente el ámbito educativo con el mundo laboral, mediante una 
formación por competencias laborales que favorezca la pertinencia de la educación, facilitando la inserción laboral más efectiva. Para lograr dichos propósitos, la OCDE desarrolla el año 2005 el proyecto denominado «Definición y selección de Competencias» (DeSeCo), para orientar el desarrollo de su PES (Martí-Noguera et al., 2014).

Igualmente, otro de los organismos supranacionales que ha contribuido al estudio e implementación de la RSU en Latinoamérica a comienzos del nuevo Milenio, fue el Banco Interamericano de Desarrollo (BID) (Gaete, 2016; Gómez et al., 2018; Martí-Noguera y Martí-Vilar, 2013; Licandro y Yepes, 2018; Soto, 2018; Vallaeys, 2014 y 2018; Vallaeys y Álvarez, 2019). Uno de los aportes más destacados de esta iniciativa, fue la publicación del libro «Responsabilidad Social Universitaria. Manuel de Primeros Pasos», elaborado por Vallaeys, De la Cruz y Sasia (2009), que propone un modelo de gestión de la RSU a partir de la identificación de los impactos generados por el quehacer universitario, respecto de cuatro grandes ejes: Campus Responsable, Formación Profesional y Ciudadana, Gestión Social del Conocimiento y Participación Social (Duque y Cervantes-Cervantes, 2020; Gaete, 2016; Gómez et al., 2018; Martí-Noguera y Martí-Vilar, 2013).

Del mismo modo, las Naciones Unidas desarrollan los Principios para la Educación Responsable en Gestión, con el propósito de orientar a las IES que poseen Escuelas de Negocios, que forman a las personas que se desempeñarán como Gerentes de Empresas, para incorporar en su formación aspectos relacionados con la responsabilidad social (Gaete, 2016; González et al., 2015; Larrán y Andrades, 2017).

Finalmente, es posible consolidar los diferentes aportes desarrollados por organismos supranacionales descritos anteriormente, con la aprobación de la Guía ISO 26.000 sobre responsabilidad social publicada el año 2010, que si bien está dirigida a todo tipo de organizaciones, también ha orientado el debate sobre la RSES en la última década (Martí-Noguera et al., 2018; Martí-Noguera y Martí-Vilar, 2013; Vallaeys, 2014; Vallaeys y Álvarez, 2019; Zamudio y Figueroa, 2020).

\subsection{Replicabilidad de la PES sobre RSES de la UNESCO}

Uno de los ámbitos para analizar la replicabilidad de la PES sobre RSES de la UNESCO, es en la base de datos UNESDOC, administrada por dicho organismo supranacional. $\mathrm{Al}$ realizar una búsqueda relacionada con el término RSES, se obtiene un total de 64 documentos, de los cuales 8 están directamente relacionados con la responsabilidad social, publicados entre 1998 y 2018, según se observa en la Figura 6.

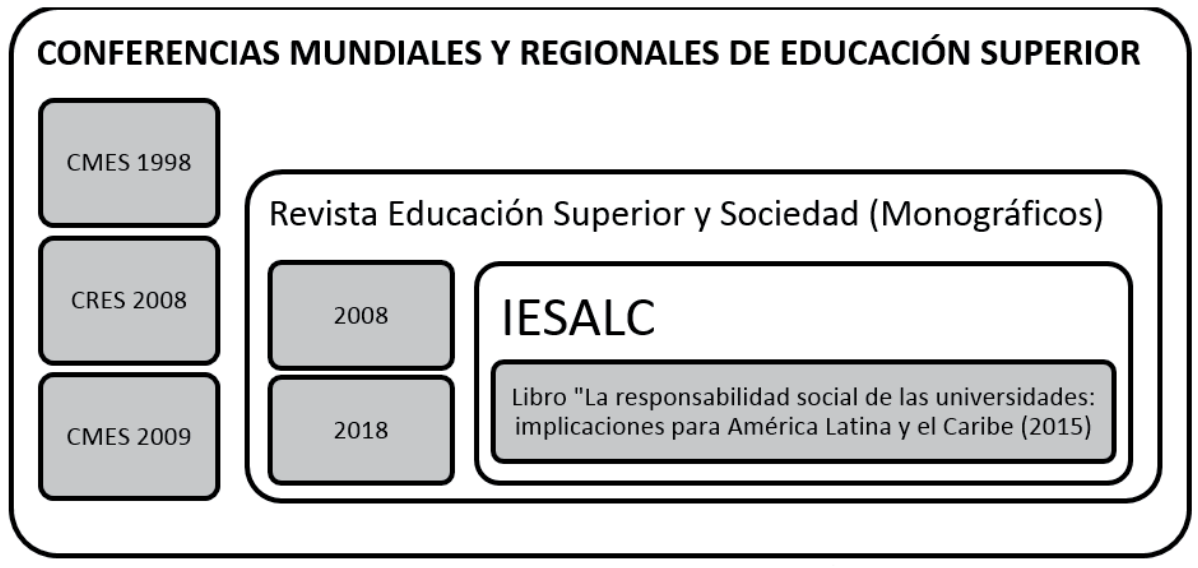

Figura 6. Documentos sobre RSES en UNESDOC. Elaboración propia. 
Además de las Declaraciones de las CMES del 1998 y 2009 analizadas anteriormente, en la Figura 6 se identifica a los monográficos editados por la Revista Educación Superior y Sociedad (RESS). El primero de ellos se publicó el año 2008, denominado: «El movimiento de responsabilidad social de la universidad: una comprensión novedosa de la misión universitaria».

Así por ejemplo, De la Cruz y Sasia (2008), enfatizaban la importancia de no aplicar modelos empresariales de responsabilidad social a las universidades, pero tampoco caer en un extremo parternalista meramente asistencial o caritativo. En cambio, las IES debían orientarse hacia la justicia social, afirmando que «...siendo la universidad una institución que influye en la sociedad, es responsable de canalizar esa influencia con una clara orientación transformadora hacia los ámbitos de vulnerabilidad social y económica presentes en nuestras sociedades» (p.27). Por ello, estos autores afirman que la RSU debe materializarse en un contexto más amplio de carácter ético, que relacione la misión y visión institucional con las necesidades sociales existentes en su territorio, identificando un triple significado de la RSU: consecuencialista, contractual y prospectivo.

En el mismo monográfico, Jiménez (2008) describe los principales aprendizajes y resultados de la experiencia chilena denominada «Universidad Construye País» (UCP) desarrollada entre los años 2000 al 2008, iniciativa reconocida por diversos especialistas como uno de los referentes de la RSU en América Latina (Gaete, 2016; Vallaeys y Álvarez, 2019), identificando 11 principios y valores y definiéndola como:

«La capacidad que tiene la universidad, de difundir y poner en práctica un conjunto de principios y valores generales y específicos, por medio de cuatro procesos considerados claves en la Universidad, como son la gestión, la docencia, la investigación y la extensión universitaria. Respondiendo Socialmente así, ante la propia comunidad universitaria y el país donde está inserta» (p.144).

También, Vallaeys (2008) reflexionaba sobre la dinámica polimorfa y multisectorial de la responsabilidad social, que genera confusiones con la acción social solidaria o una postura ideológica determinada, especialmente para imponer un modelo de tipo empresarial a las IES. Por ello, el autor vincula el concepto de responsabilidad social con tres aspectos esenciales: 1) normas éticas de desarrollo humano sostenible, 2) gestión de impactos de la organización y 3) participación de las partes interesadas. Además, define a la RSU como:

«Una política de mejora continua de la Universidad hacia el cumplimiento efectivo de su misión social mediante 4 procesos: Gestión ética y ambiental de la institución; Formación de ciudadanos responsables y solidarios; Producción y difusión de conocimientos socialmente pertinentes; Participación social en promoción de un Desarrollo más humano y sostenible» (p.209).

Posteriormente, el año 2018 la RESS edita un nuevo monográfico denominado «Cadena de valor universitaria como eje de responsabilidad social», describiendo diferentes experiencias universitarias latinoamericanas, sustentadas en modelos de gestión organizacional como la ventaja competitiva o la Nueva Gestión Pública. Así, resulta interesante lo planteado por Licha (2017, p.155) respecto de la RSU frente a los ODS 2030, afirmando que: 
«Las capacidades científico-técnicas de las universidades permiten asegurar aportes específicos referidos a: i) crecimiento económico (diversificación de la matriz productiva; cierre de brechas de productividad y competitividad, innovación tecnológica) ii) Avance de la cooperación, integración productiva y tecnológica; iii) Reducción de pobreza y desigualdad; iv) Equidad en el acceso a bienes públicos; v) acceso a la información y el fomento de la participación ciudadana; vi) Diálogo con los actores para favorecer la coherencia y legitimidad de las políticas».

Asimismo, la UNESCO promueve la RSES en Latinoamérica a través del Instituto Internacional para la Educación Superior de América Latina y el Caribe (IESALC), cuya misión fundamental es el fomento de políticas de ES que favorezcan el desarrollo sostenible, a través de la producción y transferencia del conocimiento (Aponte, 2015; Núñez y Bermúdez, 2019). Así, el IESALC y la UNESCO publican un libro editado por Aponte (2015) sobre las implicaciones de la responsabilidad social para las universidades en América Latina y el Caribe. En dicho texto, Henríquez (2015), afirma que el IESALC define a la RSU como un «...compromiso institucional autónomo, pero participativo de personas e instituciones, para orientar el cumplimiento misional hacia la pertinencia social y la gestión ética transparente, de cara a los retos de equidad y a los desafíos ambientales de la sociedad local y global» (p.17).

Otra de las acciones relevantes del IESALC en el contexto de la estrategia de replicabilidad de la PES de RSES de la UNESCO en Latinoamérica, es la realización de la Conferencia Regional de Educación Superior (CRES), como instancia reflexiva de carácter regional preparatoria para retroalimentar la realización de la CMES.

Según Tünnermann (2010), la CRES del año 1996 realizada en La Habana - Cuba, buscó reposicionar a la ES en la agenda pública latinoamericana, asumiendo el paradigma del desarrollo humano sostenible, donde las IES juegan un rol fundamental en la obtención de un crecimiento económico justo, equitativo y solidario, basado en el conocimiento, contribuyendo a la configuración de una cultura para la paz. Sin embargo, el diagnóstico de la CRES de 1996 para la región, confirmaba algunas tendencias globales importantes: expansión de la matrícula, desigualdad en la democratización del conocimiento, baja inversión pública y una creciente participación del sector privado en ES.

De acuerdo con Tünnermann (2010), el año 2008 se celebra en Cartagena - Colombia la segunda CRES latinoamericana, en la que participaron 3.500 representantes de la comunidad académica regional, con el propósito de elaborar propuestas para la CMES del 2009, proclamando en su Declaración Final que la ES debe ser considerada como un derecho humano y un bien público y social garantizado por el Estado, guiando a los países latinoamericanos hacia el desarrollo sostenible. Asimismo, Valarezo y Túñez (2014) afirman que en la CRES del año 2008, se estableció que la ES se transforma en un instrumento estratégico para alcanzar un desarrollo más sustentable, planteando como desafío trabajar en la definición de un modelo de RSU para la Región.

Recientemente, el año 2018 se celebra en Córdoba - Argentina una nueva CRES, en donde se reafirman los acuerdos previos de las CRES de 1996 y 2008, así como la CMES del 2008, ratificando que la ES debe ser considerada como un bien público social, un derecho humano y universal, así como un deber de los Estados de la Región.

Otra de las acciones concretas desarrolladas por la UNESCO para replicar la PES sobre RSES, es la creación del Observatorio de Responsabilidad Social en América Latina (ORSALC) el año 2012, dependiente del IESALC. El propósito fundamental del ORSALC 
es identificar y compartir las buenas prácticas de responsabilidad social de las IES de la Región (Martí-Noguera y Martí-Vilar, 2013; Navarro et al., 2017; Soto, 2018).

De acuerdo con Grimaldo (2017), el ORSALC realiza un Foro Regional anual itinerante en Latinoamérica, para intercambiar experiencias sobre las tendencias y evidencias relacionadas con la «Responsabilidad Social Territorial» (RST). A la fecha, se han organizado un total de siete Foros Regionales, entre los años 2013 al 2019. Así, la RST establece una nueva fase evolutiva en el concepto de RSES planteado por la propia UNESCO el año 2009, afirmando que en dicho concepto:

«El énfasis se encuentra principalmente en la valoración y valorización del aporte, transformador y autotransformador, de la Universidad a la construcción del Territorio Socialmente Responsable (TSR), noción que opera con efecto aglutinante y de retroalimentación de conceptos tales como responsabilidad social, desarrollo sostenible, ciudadanía responsable, democracia de proximidad, gobernanza. En relación con la universidad, la RST constituye el marco para repensar y enriquecer la operatividad de la RSU, superando su visión sectorial y transformándola en un efectivo aporte al territorio como espacio de aprendizaje, de valoración, de armonización y de transformación» (Grimaldo, 2017, p.192).

Asimismo, Navarro et al. (2017), afirman que las diferentes acepciones utilizadas para definir a la responsabilidad social a nivel global, ha llevado a la UNESCO a elaborar un concepto más integrador mediante la RST, para enfatizar el eje territorial de su Agenda para el cuatrienio 2016-2020. Esto con el propósito de identificar, desarrollar e implementar buenas prácticas relacionadas con el quehacer de las diferentes organizaciones que coexisten en un contexto territorial situado y específico, con una perspectiva más sistémica relacionada con el Desarrollo Sostenible, plasmado en los 17 ODS 2030 (Represas, 2015b), para que las IES materialicen contribuciones efectivas para avanzar hacia la consecución de dichos propósitos globales (Núñez y Bermúdez, 2019).

También, la red interuniversitaria URSULA ha publicado recientemente su Modelo de Gestión transversal de la RSU, identificando a los 17 ODS como ejes orientadores de las estrategias, herramientas e indicadores que permitan a las IES fortalecer su comportamiento socialmente responsable (Vallaeys, 2020).

Finalmente, a partir del llamado de la UNESCO para fortalecer la RSES a nivel mundial, se desarrollan a nivel latinoamericano algunas experiencias institucionales de carácter reticular, que asumen un rol promotor e investigador de las experiencias de RSU en la Región. Tal es el caso de la Asociación de Universidades Confiadas a la Compañía de Jesús en América Latina (AUSJAL), vigente desde el año 1985 a la fecha e integrada por 30 universidades, desarrollando un sólido marco conceptual y metodológico de la RSU (Licandro y Yepes, 2018; Martí-Noguera y Martí-Vilar, 2013). También, el caso más reciente es la creación de la Unión de Responsabilidad Social Universitaria Latinoamericana (URSULA) el año 2016, integrada actualmente por 185 IES y organizaciones adheridas (Gaete, 2016; Gaete y Álvarez, 2019; Gómez et al., 2018; Vallaeys, 2018; Vallaeys y Álvarez, 2019).

\subsection{Impacto de la PES sobre RSES de la UNESCO en Latinoamérica}

Según Martí-Noguera, Calderón y Fernández-Godenzi (2018), países iberoamericanos como Brasil, España y Perú evidencian avances en la incorporación de la RSU en sus 
respectivas legislaciones nacionales sobre ES. Según estos autores, Brasil es el primer país latinoamericano en incorporar dicha temática en sus normativas universitarias.

Para identificar el impacto de la UNESCO en las Leyes de ES en la Región, analizamos el caso de 11 países latinoamericanos, según lo expuesto en la Tabla 1.

Tabla 1.

Incorporación de la RSES en las leyes de ES de países latinoamericanos.

\begin{tabular}{|c|c|c|c|c|c|c|c|c|c|c|c|}
\hline $\begin{array}{c}\text { Ítems analizados / } \\
\text { Países Latinoamericanos }\end{array}$ & & 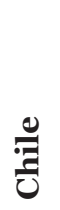 & $\frac{\pi}{\frac{\pi}{0}}$ & 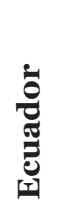 & 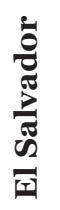 & 胥 & 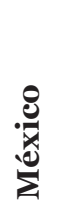 & 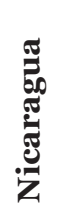 & 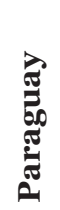 & 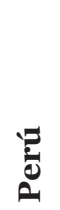 & 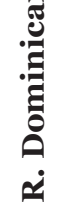 \\
\hline $\begin{array}{l}\text { Incluye explícitamente el término «Responsab- } \\
\text { ilidad Social» }\end{array}$ & & & & $\mathrm{X}$ & & & & & & $\mathrm{X}$ & \\
\hline Declara a la ES como bien público & $\mathrm{X}$ & & $\mathrm{X}$ & $\mathrm{X}$ & & & $\mathrm{X}$ & $\mathrm{X}$ & $\mathrm{X}$ & $\mathrm{X}$ & $\mathrm{X}$ \\
\hline $\begin{array}{l}\text { Liderazgo de IES en la creación de conocimiento } \\
\text { sobre problemáticas globales }\end{array}$ & $\mathrm{X}$ & $\mathrm{X}$ & & $\mathrm{X}$ & & & & & & $\mathrm{X}$ & $\mathrm{X}$ \\
\hline Promueve pensamiento crítico y ciudadanía activa & $\mathrm{X}$ & $\mathrm{X}$ & $\mathrm{X}$ & & & & & & $\mathrm{X}$ & $\mathrm{X}$ & $\mathrm{X}$ \\
\hline Contribuye al Desarrollo Sostenible & & $\mathrm{X}$ & & $\mathrm{X}$ & & & & & & $\mathrm{X}$ & $\mathrm{X}$ \\
\hline Hace realidad los DD.HH. & & $\mathrm{X}$ & & & & & & & $\mathrm{X}$ & $\mathrm{X}$ & $\mathrm{X}$ \\
\hline $\begin{array}{l}\text { Forma ciudadanos éticos, democráticos, com- } \\
\text { prometidos con la paz y los DD.HH. }\end{array}$ & $\mathrm{X}$ & $\mathrm{X}$ & $\mathrm{X}$ & $\mathrm{X}$ & $\mathrm{X}$ & $\mathrm{X}$ & & $\mathrm{X}$ & $X$ & $X$ & $\mathrm{X}$ \\
\hline $\begin{array}{l}\text { Transparencia y acceso a la información sobre } \\
\text { las IES }\end{array}$ & & $X$ & $\mathrm{X}$ & $X$ & $\mathrm{X}$ & & & & $X$ & $X$ & $\mathrm{X}$ \\
\hline $\begin{array}{l}\text { Garantiza Autonomía, Calidad, Pertinencia y } \\
\text { Eficacia de IES }\end{array}$ & $\mathrm{X}$ & $\mathrm{X}$ & $X$ & $X$ & $\mathrm{X}$ & & & $X$ & $X$ & $X$ & $\mathrm{X}$ \\
\hline
\end{tabular}

Fuente: Elaboración propia.

Según la Tabla 1, Ecuador y Perú son los únicos países latinoamericanos que incorporan explícitamente el término «responsabilidad social», en los textos de sus Leyes de ES, transformándose en el principal desafío de la PES de RSES de la UNESCO en Latinoamérica. También, nos parece destacable el caso de la República Dominicana, la que si bien no explicita el término responsabilidad social, incorpora todos los demás aspectos enunciados por UNESCO en la Declaración de la CMES del 2009.

Por otra parte, entre los aspectos propuestos por la UNESCO (2009), la formación de ciudadanos éticos y democráticos, así como la autonomía y la calidad, están incluidos en la mayoría de las Leyes latinoamericanas de ES analizadas. Al contrario, los roles y responsabilidades de las IES relativos al desarrollo sostenible y los DD.HH., se transforman en desafíos importantes de incorporar explícitamente en dichos cuerpos normativos.

En cuanto al uso del término responsabilidad social, la ley de ES ecuatoriana en el contexto de la autonomía responsable, señala que su ejercicio deberá efectuarse observando una serie de principios, entre los que incluye a la responsabilidad social (art. 17). No obstante, la ley analizada no aporta una definición explícita de dicho principio, ni la manera en la cual debe plasmarse en la autonomía de las IES ecuatorianas.

En el caso de Perú, la Ley Universitaria 30.220 del año 2014, en el Art. 6 sobre los Fines de la Universidad, señala que uno de los propósitos de las universidades peruanas es «...Formar profesionales de alta calidad de manera integral y con pleno sentido de 
responsabilidad social de acuerdo a las necesidades del país». Más adelante, en el art.124 la ley define a la RSU como:

«La gestión ética y eficaz del impacto generado por la universidad en la sociedad debido al ejercicio de sus funciones: académica, de investigación y de servicios de extensión y participación en el desarrollo nacional en sus diferentes niveles y dimensiones; incluye la gestión del impacto producido por las relaciones entre los miembros de la comunidad universitaria, sobre el ambiente, y sobre otras organizaciones públicas y privadas que se constituyen en partes interesadas».

Asimismo, la ley de ES peruana identifica los medios para la promoción de la RSU en el Art. 125 del Capítulo XIII, entre los que destaca destinar el $2 \%$ del presupuesto de cada IES para financiar proyectos y fondos concursables sobre responsabilidad social. Además, señala que la RSU se expresa en estándares de acreditación institucional (Martí-Noguera, Calderón y Fernández-Godenzi, 2018; Navarro et al., 2017; Vallaeys, 2018; Vallaeys y Álvarez, 2019).

Finalmente, fuera del ámbito de las leyes de ES analizado anteriormente en la Tabla 1, Martí-Noguera, Calderón y Fernández-Godenzi (2018), señalan que el caso brasileño de incorporación de la RSES a la legislación, se materializa en su identificación como una de las dimensiones que son evaluadas a las IES brasileñas en el contexto del Sistema Nacional de Evaluación de la Educación Superior (SINAES), instaurado en Brasil a través de la Ley 10.861 del año 2004, que regula específicamente dicho sistema. No obstante, los mismos autores reconocen que la incorporación de la RSES en la legislación brasileña no estuvo exenta de polémicas (Calderón et al., 2011), con ausencia de una nitidez conceptual y procedimental para comprender claramente cómo se implementaría concretamente en la evaluación del quehacer de las IES brasileñas.

\section{Discusión}

Los antecedentes expuestos anteriormente, evidencian que a partir de la Declaración de la CMES del año 2009, la UNESCO expone explícitamente importantes lineamientos y propuestas para el desarrollo de una PES sobre la RSES a nivel mundial (Duque y Cervantes-Cervantes, 2019; Gaete, 2014 y 2016; Gómez, Alvarado y Pujols, 2018; MartíNoguera, Calderón y Fernández-Godenzi, 2018; Navarro et al., 2017; Salazar, 2016; Soto, 2018; Urdaneta et al., 2016).

$\mathrm{Al}$ analizar la influencia supranacional de la UNESCO respecto de la RSES en las IES latinoamericanas, especialistas como Navarro et al., (2017) la describen como limitada y poco significativa. Lo anterior, puede comprobarse por ejemplo a través del estudio bibliométrico desarrollado por Duque y Cervantes-Cervantes (2019), quienes concluyen que el modelo de RSU basado en los impactos del quehacer universitario sobre las partes interesadas, desarrollado por Vallaeys et al. (2009) es la propuesta metodológica más influyente en la Región.

Otro indicador relevante para valorar el impacto de la PES sobre RSES de la UNESCO en Latinoamérica, es el bajo número de leyes de ES que incorporan explícitamente a la responsabilidad social, como un elemento normativo del funcionamiento de las IES latinoamericanas. Sin duda alguna, en dicho contexto destaca el caso de Perú como el único país latinoamericano que ha incorporado la RSU en la legislación de ES (Martí-Noguera, Calderón y Fernández-Godenzi, 2018; Navarro et al., 2017; Vallaeys, 2018; Vallaeys y Álvarez, 2019). 
Así, dentro de las áreas clave de trabajo para fortalecer el impacto de la PES sobre RSES de la UNESCO en Latinoamérica en el futuro, es posible mencionar:

1. Inexistencia de un organismo supranacional similar a la Unión Europea, que coordine el funcionamiento de los sistemas de ES de los países latinoamericanos, para implementar este tipo de PES que armonice las estructuras y currículos educativos a nivel regional. Lo anterior, a pesar de que como se indicó en el artículo, existen diversos procesos de integración subregional actualmente en desarrollo, tales como MERCOSUR, UNASUR o la Comunidad Andina de Naciones (CAN), ninguno de dichos bloques ha logrado avanzar efectivamente en la configuración formal de un Espacio Latinoamericano de ES similar al EEES, para implementar este tipo de PES (Fernández y Coppola, 2013; Valarezo y Túñez, 2014). Además, un ámbito importante para que la UNESCO pueda avanzar en el fortalecimiento de la PES analizada, será la consolidación de las redes interuniversitarias desarrolladas en el contexto de dicho organismo supranacional, específicamente a través de la CRES o el IESALC, favoreciendo la coordinación institucional para afianzar a la RSES en los países latinoamericanos.

2. La resistencia que genera en el ámbito académico latinoamericano la implementación de modelos neoliberales que puedan relacionarse con la mercantilización de la ES, como el de la RSU (Vallaeys, 2008 y 2014). Lo anterior, como consecuencia de los efectos de las diferentes tendencias mundiales que han afectado a la ES en las últimas décadas, que en casos extremos como el de Chile, las universidades privadas reciben más financiamiento del Estado vía voucher, que las propias universidades estatales (Brunner y Labraña, 2018; Espinoza y González, 2016; Lemaitre et al., 2015). En este sentido, resultará importante consolidar la perspectiva de bien común de la ES en el contexto de los ODS 2030, así como el fortalecimiento del rol del Estado respecto de las IES latinoamericanas.

3. Clarificar el carácter polisémico del concepto de RSES identificado en la literatura, que en el caso del sistema universitario latinoamericano actualmente pareciera estar dividido entre dos grandes propuestas conceptuales: la RSU, que se ha consolidado en la literatura científica en los últimos 20 años y que exponen actualmente diferentes redes interuniversitarias regionales, tales como AUSJAL y URSULA (Gaete, 2016; Gaete y Álvarez, 2019; Gómez et al., 2018; Licandro y Yepes, 2018; Martí-Noguera y Martí-Vilar, 2013; Vallaeys, 2018; Vallaeys y Álvarez, 2019). Por otra parte, la RST promocionada por el ORSALC desde el 2015, a partir del interés de la UNESCO en fortalecer las contribuciones de las IES al logro efectivo de los ODS 2030 (Grimaldo, 2017; Navarro et al., 2017). Sin embargo, ambas propuestas conceptuales coinciden en relacionar el avance del desarrollo sostenible de la sociedad con el rol de las IES en dicho contexto.

$\mathrm{Al}$ respecto, es recomendable consolidar los estudios e investigaciones sobre la RST en la Región, para describir los diferentes aspectos y características que sustentan dicha propuesta conceptual, a partir de los aportes generados en las redes interuniversitarias instaladas por UNESCO, a través de la CRES y especialmente a través del IESALC, pero también consolidando los avances obtenidos por la RSU.

En conclusión, respecto de nuestro interés por analizar la influencia supranacional de la PES de la UNESCO sobre RSES en Latinoamérica, el análisis documental desarrollado respecto de las Declaraciones de las CMES, así como las publicaciones científicas contenidas en UNESDOC, configuran un corpus teórico contundente y claro sobre la contribución y relevancia de dicho organismo supranacional en la temática analizada, 
que ha guiado en las últimas décadas al movimiento académico latinoamericano que analiza dicho campo de estudio. Sin embargo, lo anterior no ha implicado una incorporación efectiva de la RSES a los respectivos marcos legales de los sistemas de ES de los países latinoamericanos, provocando que dicha influencia se disipe y no se materialice en acciones gubernamentales nacionales o supranacionales concretas en la Región.

Finalmente, las proyecciones sobre investigaciones futuras relacionadas con la PES de la UNESCO analizada en este estudio, pueden orientarse hacia el monitoreo de las contribuciones de las IES latinoamericanas para el logro de los ODS 2030, así como respecto de las políticas públicas de los Estados que garanticen a la ES como un bien común y un derecho humano de las personas que estudian en la Región.

\section{Referencias}

Aponte, E. (Ed.) (2015). La responsabilidad social de las Universidades: Implicaciones para América Latina y el Caribe. Puerto Rico: UNESCO-IESALC.

Beltrán-Llevador, J., Íñigo-Bajo, E. y Mata-Segreda, A. (2014). La responsabilidad social universitaria, el reto de su construcción permanente. Revista Iberoamericana de Educación Superior (RIES), 5(14), 3-18. Recuperado de http://www.scielo.org. $\mathrm{mx} / \mathrm{pdf} /$ ries/v5n14/v5n14a1.pdf

Biacchi, E., Carta, L. y Buttendorff, A. (2018). Supranacionalidad y derechos fundamentales: efectividad del derecho derivado en la Comunidad Andina y en el sistema de integración Centroamericano. Estudios Constitucionales, 16(1), 99-128. http://dx.doi.org/10.4067/So718-52002018000100099

Brunner, J.J. y Labraña, J. (2018). Financiamiento de la educación superior, gratuidad y proyecto de nuevo crédito estudiantil. Debates de Política Pública $\mathrm{N}^{\circ} 31$. Santiago de Chile: Centro de Estudios Públicos. Recuperado de https://www.cepchile.cl/ cep/site/docs/20181115/20181115124945/dpp_031_noviembre2018_jjbrunner_ jlabrana.pdf

Calderón, A.; Pedro, R.; Vargas, M. (2011). Responsabilidade social da Educação Superior: a metamorfose do discurso da UNESCO em foco. Interface Comunicação Saúde Educação,15(39),1185-1198.https://doi.org/10.1590/S1414-32832011000400017

Carrasco, A. (2017). Los nuevos modelos de gobernanza universitaria. El caso de la Unión Europea como organismo supranacional que configura el sistema universitario español. Journal of Supranational Policies of Education, Extraordinario, 107-122. https://doi.org/10.15366/jospoe2017.m1

Colomo, E. y Esteban, F. (2020). La Universidad Europea: entre Bolonia y la Agenda 2020. Revista Española de Educación Comparada, 36, 54-73. https://doi. org/10.5944/reec.36.2020.26179

D’Ascanio, V. (2017). ¿Cómo se idea el Espacio Educativo Europeo? El discurso supranacional y la construcción del Espacio Europeo de Educación Superior. Journal of Supranational Policies of Education, Extraordinario, 81-106. https:// doi.org/10.15366/jospoe2017.m1 
Dávila, P., Naya, L. y Altuna, J. (2015). Las políticas supranacionales de UNICEF, infancia y educación. BORDÓN Revista de Pedagogía, 67(1), 25-38. DOI: 10.13042/ Bordon.2015.67102

De la Cruz, C. y Sasia, P. (2008). La responsabilidad de la universidad en el proyecto de construcción de una sociedad. Revista Educación Superior y Sociedad, 13(2), 16-52. Recuperado de: http://www.iesalc.unesco.org/ess/index.php/ess3/issue/ view/37

Diago, F. (2013). De la visión a la acción. Declaración Mundial sobre la Educación Superior. Revista Punto de Vista, 6, 173-183. Recuperado de https://dialnet. unirioja.es/ejemplar/372152

Dima, G. (2015). Estudio comparado sobre la responsabilidad social de las universidades en Europa y desarrollo de un marco de referencia comunitario. Informe Final EU-USR. Recuperado de http://www.eu-usr.eu/wp-content/uploads/2015/o4/ D1.4-Final-Report-Public-Part-ES.pdf

Duque, P. y Cervantes-Cervantes, L.S. (2019). Responsabilidad Social Universitaria: una revisión sistemática y análisis bibliométrico. Estudios Gerenciales, 35(153), 451464. https://doi.org/10.18046/j.estger.2019.153.3389

Espinoza, O. y González, L. (2016). La educación superior en Chile y la compleja transición desde el régimen de autofinanciamiento hacia el régimen de gratuidad. Revista Latinoamericana de Educación Comparada, 7(10), 35-51. Recuperado de http:// www.saece.com.ar/relec/revistas/10/art2.pdf

Fernández, N. y Coppola, N. (2013). Desafíos para la construcción del Espacio Latinoamericano deEducación Superior en el marco delas políticas supranacionales. Journal of Supranational Policies of Education, 1, 67-82. Recuperado de https:// revistas.uam.es/index.php/jospoe/article/view/5620

Fernández-Díaz, M.J., Rodríguez-Mantilla, J. y Martínez-Zarzuelo, A. (2016). PISA y TALIS ¿ंcongruencia o discrepancia? RELIEVE Revista Electrónica de Investigación y Evaluación Educativa, 22(1), 1-16. http://dx.doi.org/10.7203/relieve.22.1.8247

Gaete, R. (2014). La responsabilidad social universitaria como política pública: Un estudio de caso. Revista Documentos y Aportes en Administración Pública y Gestión Estatal, 14(22), 103-127. Recuperado de https://www.redalyc.org/ pdf/3375/337531584004.pdf

Gaete, R. (2016). Iniciativas internacionales y redes interuniversitarias de responsabilidad social universitaria. Revista Ciencia, Docencia y Tecnología, 27(53), 75-102. Recuperado de http://www.pcient.uner.edu.ar/cdyt/article/view/171

Gaete, R. (2020). Dirección por valores y responsabilidad social en universidades estatales chilenas. Revista Digital de Investigación en Docencia Universitaria, 14(1), 1-14. https://doi.org/10.19083/ridu.2020.1073 
Gaete, R. y Álvarez, J. (2019). Responsabilidad social universitaria en Latinoamérica. Los casos de URSULA y AUSJAL. Revista Actualidades Investigativas en Educación, 19(3), 1-27. http://dx.doi.org/10.15517/aie.v19i3.38637

Global University Network for Innovation (GUNI) (2009). La educación superior en tiempos de cambio. Nuevas dinámicas para la responsabilidad social. Barcelona: Mundi-Prensa.

Gómez, L. M., Alvarado, Y. \& Pujols, A. (2018). Practicando la responsabilidad social universitaria en el Caribe: Perspectivas de los públicos internos. Revista Digital de Investigación en Docencia Universitaria, 12(1), 96-118. http://dx.doi. org/10.19083/ridu.12.714

González, Ó., Fontaneda, I., Camino, M. y Revilla, A. (2015). La responsabilidad social en las universidades españolas 2014/15. Serie Investigaciones. Madrid: IAES. Recuperado de http://www3.uah.es/iaes/publicaciones/essays_012.pdf

Grimaldo, H. (2017). La Responsabilidad Social Territorial: aprendizaje, armonización y transformación. Revista Educación Superior y Sociedad, 26, 175-199. Recuperado de http://www.iesalc.unesco.org/ess/index.php/ess3/article/view/73

Henríquez, P. (2015). Prólogo Responsabilidad social de la universidad: uno de los requisitos para ser universidad, pp.15-29. Aponte, E. (Ed.) (2015). La responsabilidad social de las Universidades: Implicaciones para América Latina y el Caribe. Puerto Rico: UNESCO-IESALC.

Jiménez, M. (2008). ¿Cómo medir la percepción de la responsabilidad social en los diversos estamentos de la universidad?: una experiencia concreta. Revista Educación Superior y Sociedad, 13(2), 140-161. Recuperado de http://www.iesalc. unesco.org/ess/index.php/ess3/issue/view/37

Larrán, M. y Andrades, F. (2017). Analyzing the literature on university social responsibility: A review of selected higher education journals. Higher Education Quarterly, 71, 302-319. https://doi.org/10.1111/hequ.12122

Lemaitre, M., Zenteno, M., Torre, D., Cassorla, I. y Alvarado, A. (2015). Sistemas de educación superior y mecanismos de financiamiento. Elementos para una discusión sobre gratuidad en la educación superior. Santiago de Chile: CINDA. Recuperado de https://cinda.cl/wp-content/uploads/2015/o1/sistemas-de-educacion-superiory-mecanismos-de-financiamiento-elementos-para-una-discusion-sobre-gratuidaden-la-educacion-superior.pdf

Licandro, O y Yepes, S. (2018). La Educación Superior conceptualizada como bien común: el desafío propuesto por UNESCO. Revista Digital de Investigación en Docencia Universitaria, 12(1), 6-33. http://dx.doi.org/10.19083/ridu.12.715

Licha, I. (2017). Responsabilidad social de las universidades latinoamericanas y objetivos de desarrollo sostenible: oportunidades de desafíos. Revista Educación Superior y Sociedad, 29, 145-162. Recuperado de http://www.iesalc.unesco.org/ess/index. $\mathrm{php} / \mathrm{ess} 3 /$ article/view/95/92 
López, F. (2012). La Segunda Conferencia Mundial de Educación Superior (UNESCO, 2009) y la visión del concepto de acreditación en las conferencias de UNESCO (1998-2009). Avaliação, 17(3), 619-636. http://dx.doi.org/10.1590/S141440772012000300004

Martí-Noguera, J.J., Calderón, A. y Fernández-Godenzi, A. (2018). La responsabilidad social universitaria en Iberoamérica: análisis de las legislaciones de Brasil, España y Perú. Revista Iberoamericana de Educación Superior (RIES), 9(24), 107-124. https://doi.org/10.22201/iisue.20072872e.2018.24.267

Martí-Noguera, J.J. y Gaete-Quezada, R. (2019). Construcción de un sistema de educación superior socialmente responsable en América Latina: Avances y desafíos. Revista Archivos Analíticos de Políticas Educativas, 27(97), 1-29. https://doi. org/10.14507/epaa.27.3925

Martí-Noguera, J.J., Licandro, O. y Gaete-Quezada, R. (2018). La responsabilidad social de la educación superior como bien común. Concepto y desafíos. Revista de la Educación Superior, 47(186), 1-22. https://doi.org/10.36857/resu.2018.186.353

Martí-Noguera, J.J., Martí-Vilar, M. (2013). Una década de responsabilidad social universitaria en Iberoamérica. Revista Española del Tercer Sector, 25, 145-162. Recuperado de https://www.accioncontraelhambre.org/sites/default/files/ documents/25_o.pdf

Martí-Noguera, J.J., Martí-Vilar, M., Vargas Villamizar, O. y Moncayo-Quevedo, J. (2014). Reflexión sobre los discursos en educación superior, una mirada desde la psicología social crítica. Revista de la Educación Superior, 43(172), 33-55. https:// doi.org/10.1016/j.resu.2015.03.008

Martínez-Usarralde, M. J., Lloret-Catalá, C., \& Mas-Gil, S. (2017). Responsabilidad Social Universitaria (RSU): Principios para una universidad sostenible, cooperativa y democrática desde el diagnóstico participativo de su alumnado. Archivos Analíticos de Políticas Educativas, 25(75), 1-25. Recuperado de https://epaa.asu.edu/ojs/ article/view/2769

Matarranz, M. y Valle, J. (2018). Educación y supranacionalidad: Aproximación a los conceptos básicos. Journal of Supranational Policies of Education, 8, 93-107. https://doi.org/10.15366/jospoe2018.8.006

Matarranz, M., Valle, J. y Manso, J. (2020). Después del 2020... Hacia un Espacio Europeo de Educación en 2025. Revista Española de Educación Comparada, 36, 98-128. https://doi.org/10.5944/reec.36.2020.27040

Mendivil, P. (2010). Constitución, supranacionalidad y control constitucional del ordenamiento jurídico comunitario. Revista Jurídicas CUC, 6, 82-96. Recuperado de https://revistascientificas.cuc.edu.co/juridicascuc/article/view/743

Ministerio de Educación y Formación Profesional (2019). Panorama de la educación Indicadores de la OCDE. Madrid: Secretaría General Técnica. Recuperado de https:// www.educacionyfp.gob.es/dam/jcr:b8f3deec-3fda-4622-befb-386a4681b299/ panorama\%20de\%2ola\%20educaci\%C3\%B3n\%202019.pdf 
Navarro, G., Rubio, V., Lavado, S., Minnicelli, A. y Acuña, J. (2017). Razones y propósitos para incorporar la responsabilidad social en la Formación de personas y en Organizaciones en Latinoamérica. Revista Latinoamericana de Educación Inclusiva, 11(2), 51-72. Recuperado de https://scielo.conicyt.cl/pdf/rlei/v11n2/ arto5.pdf

Núñez, I. y Bermúdez, E. (2019). Valores, Responsabilidad Social Universitaria (RSU), Educación para el Desarrollo Sostenible (EDS) y Gestión de la Comunicación Organizacional. GECONTEC: Revista Internacional de Gestión del Conocimiento y la Tecnología, 7(1), 103-115. Recuperado de https://www.upo.es/revistas/index. $\mathrm{php} / \mathrm{gecontec/article/view/4059}$

Organización para la Cooperación y el Desarrollo Económico (OCDE) (2018). Docentes en Iberoamérica. Análisis de PISA y TALIS. Fundación SM: OCDE. Recuperado de https://www.oecd.org/skills/piaac/Docentes\%20en\%2oiberoame\%CC\%81rica\%20 PISA.pdf

Pereira, L. (2012). El desarrollo de la supranacionalidad. Algunos Apuntes. Revista de Derecho Constitucional Europeo ReDCE, 9(18), 199-213. Recuperado de https:// www.ugr.es/ redce/REDCE18pdf/o7_pereira_coutinho.pdf

Piacenza, M. y Silva, Y. (2013). Análisis bibliométrico sobre responsabilidad social universitaria. Psychology, Society \& Education, 5(2), 125-138. Recuperado de http://ojs.ual.es/ojs/index.php/psye/article/view/500/478

Ramos, R. (2011). La supranacionalidad en la Unión Europea. Comparación con el progreso Centro Americano de integración. Revista de Derecho, 32(1), 5-27. Recuperado de https://pdfs.semanticscholar. org/7c77/oabd5cb7d536acb3e94a7a8f7ec1fca479of.pdf

Represas, N. (2015a). Política educativa de la UNESCO: Reflexiones desde un modelo de análisis supranacional. BORDÓN Revista de Pedagogía, 67(2), 101-115. DOI: 10.13042/Bordon.2015.67207

Represas, N. (2015b). Elementos de la Unión Europea, La OCDE y la UNESCO: Análisis de carácter supranacional. Journal of Supranational Policies of Education, 3, 283306. Recuperadodehttps://repositorio.uam.es/bitstream/handle/10486/667470/ JOSPOE_3_17.pdf?sequence=1\&isAllowed $=\mathrm{y}$

Ruiz-Corbella, M. y Bautista-Cerro, M. (2016). La responsabilidad social en la universidad española. Revista Teoría de la Educación, 28(1), 159-188. http:// dx.doi.org/10.14201/teoredu2016281159188

Salazar, R. (2016). Los pilares para la educación superior del futuro: Responsabilidad social, calidad académica y servicio-aprendizaje (S-A). Revista Fides et Ratio, 11. 155-179. Recuperado de http://www.scielo.org.bo/pdf/rfer/v11n11/v11n11_a11.pdf

Soto, O. (2018). La responsabilidad social en la Universidad ecuatoriana. Revista Razón y Palabra, 22(3), 340-357. Recuperado de https://www.revistarazonypalabra. org/index.php/ryp/article/view/1275 
Torres, A. (2012). Del Estado absoluto al supranacional e internacionalmente integrado. Revista de Derecho Constitucional Europeo ReDCE, 9(18), 19-41. Recuperado de https://www.ugr.es/ redce/REDCE18pdf/o1_torres_moral.pdf

Tünnermann, C. (2010). Las conferencias regionales y mundiales sobre educación superior de la UNESCO y su impacto en la educación superior de América Latina. Revista Universidades, 6o(47), 31-46. Recuperado de https://www.redalyc.org/ articulo.oa?id=37318570005

UNESCO (Organización de las Naciones Unidas para la educación, la ciencia y la cultura) (1998). La educación superior en el siglo XXI: Visión y acción. Declaración Conferencia Mundial sobre la Educación Superior, París, 5-9 de octubre. Recuperado de https://unesdoc.unesco.org/ark:/48223/pfoooo113878_ spa?posInSet=1\&queryId=9bacbf2b-c1do-4ff6-8c2d-86fo4254edaa

UNESCO (Organización de las Naciones Unidas para la educación, la ciencia y la cultura) (2009). La nueva dinámica de la educación superior y la investigación para el cambio social y el desarrollo. Declaración Conferencia Mundial sobre la Educación Superior. París, París, 5-9 de octubre. Recuperado de https://unesdoc.unesco.org/ ark:/48223/pfoooo183277_spa?posInSet=3\&queryId=7a6db127-2e9o-42588188-c8696033e44a

Urdaneta, M., Cova, M., Chirinos, A. y González, X. (2016). Responsabilidad social en las universidades del municipio Maracaibo del estado Zulia. Revista Venezolana de Gerencia, 21(73). http://dx.doi.org/10.37960/revista.v21i73.21057

Valarezo, K. y Túñez, J. (2014). Responsabilidad social universitaria. Apuntes para un modelo de RSU. Revista de Comunicación, 13, 84-117. Recuperado de https:// minerva.usc.es/xmlui/handle/10347/18764

Vallaeys, F. (2008). Responsabilidad social universitaria: una nueva filosofía de gestión ética e inteligente para las universidades. Revista Educación Superior y Sociedad,13(2), 193-220. Recuperado dehttps://unesdoc.unesco.org/ark:/48223/ pfooo0182067

Vallaeys, F.; De La Cruz, C.; Sasia, P. (2009). Responsabilidad social universitaria. Manual de primeros pasos. México D.F.: Mc Graw Hill.

Vallaeys, F. (2014). La responsabilidad social universitaria: un nuevo modelo universitario contra la mercantilización. Revista Iberoamericana de Educación Superior (RIES), 5(12), 105-117. Recuperado de http://www.scielo.org.mx/pdf/ries/v5n12/v5n12a6.pdf

Vallaeys, F. (2018). Las diez falacias de la responsabilidad social universitaria. Revista Digital de Investigación en Docencia Universitaria, 12(1), 34-58. http://dx.doi. org/10.19083/ridu.12.716

Vallaeys, F. y Álvarez, J. (2019). Hacia una definición latinoamericana de responsabilidad social universitaria. Aproximación a las preferencias conceptuales de los universitarios. Revista Educación XX1, 22(1), 93-116. doi: 10.5944/educXX1.19442 
Vallaeys, F. (2020). Responsabilidad Social Universitaria. El modelo URSULA. Estrategias, Herramientas e indicadores. Lima: URSULA. Recuperado de http:// unionursula.org/wp-content/uploads/2019/12/ursula-modelo-responsabilidadsocial-universitaria-rsu.pdf

Valle, J. (2012). La Política Educativa Supranacional: un nuevo campo de conocimiento para abordar las políticas educativas en un mundo globalizado. Revista Española de Educación Comparada, 20, 109-144. https://doi.org/10.5944/reec.20.2012.7595

Valle, J. y Manso, J. (2013). Competencias clave como tendencia de la política educativa supranacional de la Unión Europea. Revista de Educación, Extraordinario, pp.1233. DOI: 10.4438/1988-592X-RE-2013-EXT-255

Vázquez, J. L., Aza, C. L., \& Lanero, A. (2014). Are students aware of university social responsibility? Some insights from a survey in a Spanish university. International Review on Public and Nonprofit Marketing, 11, 195-208. https://doi.org/10.1007/ s12208-014-0114-3

Villanueva, E. (2010). Perspectivas de la educación superior en América Latina: construyendo futuros. Perfiles Educativos, 32(129), 86-101. http://www.scielo. org.mx/pdf/peredu/v32n129/v32n129a6.pdf

Zamudio, F. y Figueroa, R. (2020). Génesis de la responsabilidad social y su impacto en las instituciones de educación superior de México. Revista Espacios, 41(4), 1-11. Recuperado de http://revistaespacios.com/a20v41no4/a20v41no4p22.pdf 